\title{
Hematoporphyrin Derivative
}

National Cancer Institute

\section{Source}

National Cancer Institute. Hematoporphyrin Derivative. NCI Thesaurus. Code C1377.

A complex mixture of monomeric and aggreg ated porphyrins with photosensitizing activity. Upon systemic administration, hematoporphyrin derivatives accumulate in tumor cells and, once activated by red laser light (630 nm), in the presence of oxygen, produce sing let oxygen and other reactive oxygen radicals, resulting in local radical-mediated tumor cell death. 